\title{
Managing Gas Flaring and Allied Issues in the Oil and Gas Industry: Reflections on Nigeria
}

\author{
Oyewunmi, Olabode A. \\ Department of Business Management, Covenant University, Ogun State, Nigeria \\ Email: olabode.oyewunmi@covenantuniversity.edu.ng \\ Oyewunmi, Adebukola E. \\ Department of Business Management, Covenant University, Ogun State, Nigeria \\ Email: adebukola.oyewunmi@covenantuniversity.edu.ng
}

\section{Doi:10.5901/mjss.2016.v7n4p}

\section{Abstract}

\begin{abstract}
The level of gas flaring attributable to the international oil and gas industry is without a doubt very significant. This realization, has led to a global reaction to reduce gas flaring volumes in the light of the adverse environmental, economic and social consequences connected with the high incidence of gas flaring. Hence, the approach being adopted to achieve a manageable level of gas flaring is as diverse as the respective countries that contend with this peculiar problem. The direction thus far, has been to address the gas flaring dilemma on a national, regional and international platform. Gas flaring cannot be construed in isolation, and as a consequence its consideration, has also brought to the fore matters related to environmental protection. Moreover, gas flaring has been identified as a process that damages the ozone layer, and thus contributing to escalating the global warming phenomenon. Amongst others, this notable finding has further stimulated domestic and international initiatives aimed at curbing the adverse effects of gas flaring. In Nigeria's case, there is an apparent incentive to mitigate the incidence of gas flaring in view of; the country's heavy reliance on oil and gas revenues, as well as the identifiable policy adjustments that need to be achieved on a sustained basis.
\end{abstract}

Keywords: Gas flaring, oil and gas, sustainable development, environmental protection, Nigeria

\section{Introduction}

An estimate of the volume of natural gas being flared annually on the global level, has been assessed in range of 150 billion cubic meters (World Bank, 2004). It suffices to say that this estimate will vary subject to the prevailing industry practices and policies of the affected countries involved with the development of oil and gas resources. The variance in estimates also brings to the fore, the need to institute an improved culture of disclosure and transparency in the oil and gas industry. In this regard, it is important for all the key actors to reconcile their desire to generate economic rent with the equally important matters of environmental protection, sustainability and amongst others, connected with their pecuniary interests.

Nigeria in particular, has been culpable of not effectively curbing the practice of flaring gas associated with the crude oil production. Thus, it has been opined that about 2.5 billion cubic feet of gas is being flared across various oil facilities within the country (Climate Justice, 2005). The levels of flaring being experienced in Nigeria are simply not justifiable, especially when construed in the context of the connected; considerable environmental hazards, grievous health consequences, and colossal economic losses. In the light of this negative trend, countries such as Nigeria, are still struggling with bridging the electricity generation and consumption deficit, inspite of the huge natural gas resources (World Bank, 2004). This background is a further testimony to the magnitude of the gas flaring problem and also constitutes an incentive to resolve the same.

It is also instructive to note that the evolving global gas market also lends credence to the fact that, natural gas has the long term potential of significantly contributing to the overall energy mix. This outlook has been further validated by the growth of the LNG trade, development of re-injection gas facilities, construction of vast cross-border gas pipeline networks and the commercialization of Gas to Liquid (GTL). Also, the assured volatility of the international oil prices more than any other factor is sign post as regards the gap in the market for other energy sources. All these alternatives to gas flaring, amongst others, were previously considered not to be viable and cost effective options in the management of gas 
resources (Zyuzev, 2008). The alternate energy options have now been adopted in view of the immense environmental, economic, social and developmental benefits to the countries that are contending with the challenge of reducing gas flaring to a manageable level.

The paper, in view of the background set-out above, attempts a policy and regulatory introspection into the contemporary issue of gas flaring relative to Nigeria's oil and gas industry. Due cognisance is given to the international dimension and environmental protection dynamics usually attributable to the somewhat complex gas flaring phenomenon. Hence, the paper highlights in broad respects; contractual, fiscal and regulatory options that can be deployed to manage the high incidence of gas flaring, which can be regarded in measurable respects as a negative indicator for Nigeria's, geo-political economy. Moreover, the paper also duly emphasized the issue of gas flaring as a component of some wider issues which have a bearing on the approaches being deployed to reduce gas flaring levels within the oil and gas industry.

\section{Overview on Gas Flaring}

There is still some level of controversy about the actual level of gas flaring in various oil and gas producing economies. However, what is not in dispute is the adverse impact of such practice. Specifically, gas flaring, if not duly addressed, will destroy the economic and social structures of a community. It also desecrates the natural habitat and results in varying adverse health conditions for the residents of the affected communities (Kafada, 2012). This undesirable situation still persists to certain degrees in oil production facilities domiciled in the Niger-Delta area of Nigeria. Hence, there exists concrete evidence to continually seek practical, effective and affirmative action (where required), so as to progressively lower gas flaring to levels that are not harmful to human co-existence.

Gas flaring is the burning-off of unwanted gas, commonly referred to as associated gas which is vented during production and refining of crude oil (Jorgenson, 2006). Associated gas is a combination of hydrocarbons that is released when crude oil is brought to the surface. The incidence of gas flaring typically occurs at gas plants in the course of drilling and testing of oil and gas wells. The occasion of "emergencies and equipment failures of natural gas pipelines", have also resulted in the gas being released into the atmosphere thus adding to the already huge flare ratio, globally (World Bank, 2004). The gas is burned off because it is perceived as a by-product of the process of oil exploration and development. The commonly stated alternatives to gas flaring include; (a) gathering and processing for use (b) stock piling or storing until it can be sold off where transport networks and a viable market exists; (c) re-injected into the subsoil to sustain the pressure level of the oil reservoirs during production; and (d) utilize for powering micro-turbine generators for electricity production.

Gas flaring primarily generates considerable amount of heat, a foul odour, noise, can be observed and perceived, hundreds of meters away from the production site. Unrenewable natural gas resources are lost, when it is not utilized in a cost-beneficial manner and this is coupled with appreciable damage being caused to the environment. In addition, the unregulated flaring of gas minimizes potential tax revenues and trade opportunities. The reduction of gas flaring globally, contributes to mitigating the impact of climate change, and as a result, it is urgent that high flaring countries such as Russia, Iran, Iraq, Nigeria, Venezuela, Brazil and Mexico re-energize their efforts, if a more significant impact is to be achieved (Kaldany, 2006). Hence, the models in operation in these jurisdictions should be re-appraised taking into account the corporate interest of the larger society during and after development of the oil and gas resources.

\subsection{Issues on the Reduction of Gas Flaring}

The incidence of gas flaring is a product of a multitude of factors and is primarily a manifestation of certain defects in existing institutions which are connected with the oil and gas industry. National governments in developing and mature economies alike bear the primary responsibility for developing the strategies needed to reduce $\mathrm{CO} 2$ emissions from their industry processes. Van der Veer (2008) alludes to the need for government and industry to play their respective parts in reducing $\mathrm{CO} 2$ emissions. It was also acknowledged that while the oil and gas industry must strive to improve the technology applied in developing projects, governments need to deliver effective emissions reduction policies and also create an enabling environment. Some of the specific harmful gaseous by products of oil production and consequently released into the atmosphere, amongst others include; nitrogen dioxides, sulphur dioxide, benzene, xylene, hydrogen sulphide and benzapyrene (Ojide, 2010).

The countries that are responsible for flaring associated gas as a by-product of oil production and for reasons of lack of capacity utilization are in fact limited. However, in spite of this numerical limitation, the act of gas flaring greatly impacts on the global ecological balance irrespective of where the flare activities occur. Moreover, there is a widespread 
recognition of the negative impacts of gas flaring on the global climate; such as the depletion of the ozone layer and the endangering of the human and animal biodiversity amongst others. The shared and collective responsibility to protect the environment, has resulted in a sustained drive to address the problem of gas flaring which is a primary contributing agent to the high level of $\mathrm{CO}_{2}$ in the atmosphere (Herzog, Baumert and Pershing, 2006).

The manifestation of the concern to reduce the incidence of gas flaring, has triggered action on the national level via internal regulation of the practices of the oil and gas companies by means of codes of practice, guidelines and legislation. It appears that, legislations dealing with protection of the environment and pollution in general are more prevalent, though there is now the recognition to treat the incidence of gas flaring in a class of its own. This outlook is important, in the light of attractiveness of natural gas as a viable alternative to oil, amongst other renewable energy sources. Moreover, the expediency of gas as a means of generating electricity for domestic and industrial use is also driving the efforts towards natural gas utilization (Bradley and Baumert, 2005). However, the challenges facing the introduction of "green fuels" on a commercial scale in terms of effectively competing with natural gas for a reasonable market share, is real. Moreover, the option is being perceived more in the mid- long term owing to issues of technology, financing, security of supply, and market penetration. These associated factors are important to the respective participants, in what has been known to be a highly volatile and capital intensive energy sector (Begg, Van der Woerd and Levy, 2005).

The flaring of gas into the atmosphere not only adds considerably to gas emissions; it also robs developing countries of an energy source that is relatively clean and less expensive. The volatility of oil prices further lends credence to the need for gas economies, both developing and mature, to diversify their revenue base in a bid to maintain a steady stream of income. Oil production contracts to a great degree, determine the volumes and mode of gas flaring. The respective contractual rights, obligations as well as the consequences for breach are usually captured. Contractual models or templates would typically vary among developing countries because of differences in oil project specifications economic goals. However, it not uncommon for contracts related to oil production to recognize the rights of operators use to associated gas in their oil field operations to optimize oil production (reinjecting the gas into fields or using it generate power equipment).

The right to sell associated gas to third parties has often been constrained by preemptive rights, which give the host government, (often at no cost or at a greatly reduced price), the exclusive rights to associated gas not used for field operations. Notwithstanding that a notable number of these traditional contractual arrangements have been adapted over time, preemptive rights are still captured in contracts in some developing economies. A notable imbalance created by preemptive rights, is such that, State owned utilities still lack the level of technical and financial commitment that is required to develop an integrated the gas network suitable that matches the needs of their local environment (Gerner, 2004).

Fiscal incentives can play a big role in the drive to reduce gas flaring activities in the petroleum sector. Thus, the corresponding obligations rests with the key stakeholders to honour the consequences of the applicable tax regime and various adjustments that may be introduced due to the vagaries of the operating environment. The policy outlook, preferences and drive are also issues that need to be taken into account in this regard. Specifically, fiscal incentives, are more attractive and preferable if optimal returns can be derived relative to the volume of output. In other words, if the potential for increased production is largely positive, it provides ample opportunities for tax-maneuvering or flexibility, subject to other agreed terms and conditions. Also, it is not unusual for some operators to closely analyze the economics of associated gas development separately from oil production which is in contrast to a more integrated approach of; assessing the economics of associated gas jointly with those of oil production.

Gas flaring as an operational consequence of developing oil resources is considered as a negative externality. The costs attributable to such are an important component of establishing the viability of an oil field. Moreover, projects targeted at reducing gas flaring must compete with other ventures on the portfolio of some major oil companies. Thus, host governments will need to enact and implement policies that combine cost and benefits of developing gas flaring reduction capabilities in the oil and gas industry. This approach is proffered against the background that such gas flaring reduction projects are domiciled in some of the least creditworthy countries where investors are not inclined to bear the full commercial risk. Furthermore, smaller international oil companies and some national oil companies may have difficulties self-financing or borrowing from private capital markets for these kind of projects especially where returns associated with such cannot be reasonably guaranteed.

\subsection{Gas Flaring Policy and Regulation in Nigeria}

The case of Nigeria provides a useful insight into the issues connected with management of gas flaring in a typical 
developing gas economy, especially in terms of marketing and utilization. At the time crude oil was first found in Nigeria, in 1958, there were no specific regulations in existence that could effectively regulate the exploitation, production and usage of natural gas. This is rather surprising, when viewed in the context that Nigeria can be regarded as more gas endowed relative to discovered oil resources. It is instructive to note, that Nigeria's natural gas reserves are more than twice her oil reserves (Aluko and Oyebode, 2007). Nigeria currently has a legal framework which forms the basis for the effective and practical regulation of air quality standard and natural gas conservation. The policy outlook builds on a generally accepted fact that the atmosphere is crucial for the survival and well-being of man and other leaving animals; hence the maintenance of a clean atmosphere is fundamental to having a healthy environment. The overriding implication of the policy guideline is that, it is not permissible to engage in uncontrolled activities that will destroy the sanctity of the environment. The uncontrolled flaring of gas, save for emergency and standard operational purposes, is the primary agent of environmental pollution. Hence, the necessity for a robust policy to regulate any contrary flaring activities of the various oil and gas operations within the country.

The discovery of oil in commercial quantities in Nigeria preceded the enactment of the Petroleum Act 1969 and the Petroleum (Drilling and Production) Regulations 1969 (Cap. P12 Laws of the Federation of Nigeria, 2004). Though there have been various amendments to these legislations, they are still in operation and are the principal laws regulating Nigeria's oil and gas industry. As a consequence of the global concern on the issue of gas flaring, Nigeria, one of the top fifteen producers, likewise a prime country in natural gas flaring, enacted the Associated Gas Re-injection Act 1979 ( Cap. A26, Laws of the Federation of Nigeria, 2010). The enactment of this Act was long overdue, in view of the apparent void in the pre-existing legislations which were practically silent on the question of gas utilization and management of consequential flaring associated with oil operations.

The Nigerian National Petroleum Corporation (NNPC) is the principal institution vested with the statutory authority to discharge broadly speaking, the commercial and inspectorate functions with regards to the entire oil and gas operations across the country. The NNPC also oversees the operations of the Nigeria Gas Company (NGC), one of its numerous subsidiaries, and the management of the country's participatory interests in the several joint ventures arrangements with the multinational oil companies. Nigeria's national oil company is currently undergoing varying levels of internal restructuring, and such a process, should in the long term address amongst others issues of; improved gas utilization, infrastructure financing and capacity development. The Department of Petroleum Resources (DPR) is the primary regulatory body for oil and gas operations in Nigeria. Its functions are very wide, some of which include; monitoring the quality of various oil products, compliance with industry regulations (gas flaring inclusive), inspection of operational sites and ensuring compliance with health, safety and environmental regulations in the oil and gas industry. The DPR is also responsible for issuing and renewing of permits and licenses, conducting licensing rounds and has the corresponding powers to impose fines and enforce the closure of defaulting operations.

Another regulatory body is the The Niger- Delta Development Commission (NDDC). It was established in 2002 in response to the degrading living and environmental conditions of the Niger Delta community, particularly against the background of the long history of unregulated gas flaring activities of some oil companies operating in the region. The NDDC is more or less a pressure group with some degree of statutory authority and is made up of a governing board with membership drawn from each of the States situated within the Niger Delta region. The lack of adequate human, financial resources, bureaucracy and a deficit of political will, has prevented some of these agencies from realizing their full capabilities as regards the management of gas flaring.

The issue of enforcement is a major challenge for Nigeria's regulatory authorities. This situation (i.e. weak enforcement) has been widely linked to non-compliance on the part of some multinational oil companies (MNOCs), primarily because they perceive that the consequences of not carrying out their operations according to the stipulated regulations on gas flaring reduction, is to say the least insignificant (Shinsato, 2005). Moreover, in some cases there exists an undesirable overlap of functions between/amongst some of these agencies; such that the resultant conflict in authority only goes to complicate any meaningful efforts to address gas flaring activities within the oil and gas sector in Nigeria.

Also, it cannot be over emphasized that Nigeria as a country relies heavily on revenues from oil and gas operations and this is inspite of ongoing efforts of successive administrations to diversify the revenue base. Hence, the seeming compulsion to sustain the huge revenues being derived from oil and gas activities, has progressively eroded the significance of due enforcement and compliance with a practical gas flaring legal regime amongst other associated environmental protection provisions related to this theme. A further criticism of the regulation of gas flaring in Nigeria pertains to the nature of the existing Joint Venture Agreements (JVA) between the Government and multinational corporations. The JVA were constructed in such a way as to shift a greater amount of responsibility with regards to gas re-injection or utilization, to the NNPC. The greater responsibility particularly in terms of cash calls, is implicit in its 
majority equity holding of 55\% (income and cost of production) with regard to some JVA (Malumfashi, 2007). There is however a transition away from this style of contracts, as the authorities are now more inclined towards the Production Sharing Contracts (PSC) which excludes the government from bearing the costs associated with oil operations (Omorogbe, 2003).Thus, well-structured and defined fiscal regimes will help to ensure accountability towards the reduction of gas flaring and as a result facilitate enforcement.

The issue of the unfavorable human rights situation in Nigeria also merits some treatment in the context of this study. Environmental violations, gas flaring inclusive, constitute the breach of an individual's fundamental human rights, primarily because it diminishes the individual's quality of life, and can even lead to death. In this light, the disconnect in Nigeria, between the environmental regulations on the one hand and the protection of an individual's fundamental rights on the other hand, has led to multinational corporations exploiting the status-quo and the result has been many years of unabated gas flaring with various negative consequences. An attempt to rid Nigeria of the scourge of gas flaring, can be discovered in what has been termed; the Nigerian Gas Master Plan. The underlying thrust of the policy rests on, protection of the rights and interests of the country with respect to its vast gas resources. The policy initiative lists the elimination of gas flaring as one of its cardinal objectives by which amongst other objectives, it seeks to develop the local economy and also maintain a reasonable export market through an optimal utilization of gas resources. However, the political will to follow through on the details of the plan is another matter altogether. This brings to the fore the need for all the actors (internal and external) to find pathways to ensure that the tangible benefits of the plan come to fruition.

In accordance with the issues raised earlier in this paper, there is an indispensable need to provide an adequate, political, legal, social, economic and technological environment for any policy geared towards the reduction of gas flaring, to be reasonably effective. The inability of Nigeria to manage and optimize these factors at an appreciable level has impacted negatively on the drive to reduce gas flaring within Nigeria's oil and gas sector.

\section{Recommendations and Conclusions}

The drive to address the incidence of gas flaring in the oil and gas industry is still evolving. As the various participants are coming to terms with the negative externalities associated with gas flaring, inaction can no longer be considered a desirable option. In a bid to sustain the momentum towards lowering the global gas flaring level, private sector participation is of paramount importance in terms of maintenance of economic and social development. This platform (private sector participation) serves a crucial role in helping to reduce gas flaring and by implication $\mathrm{CO}_{2}$ emissions which amongst others can be achieved by; the establishment of an effective research and development strategy. Thus, the provision of an adequate incentive framework by the government is sacrosanct, if any meaningful impact is to be made, especially in view of the capital intensive nature of the petroleum industry.

Non-governmental organizations have always played a pivotal role in environmental issues and are still relevant in the scheme of things. They are crucial in bringing to light the acts of environmental degradation by corporate organizations, and are adept at exerting due pressure on industries, governments and organizations with a view to stimulate the operators to adopt better ways of conducting business. The publicity and awareness activities would ultimately result into positive outcomes in terms of funding, human development, climate, animals etc. Moreover, it is important that the larger society is more enlightened about gas flaring, $\mathrm{CO}_{2}$ emissions, greenhouse gases and its effects, the need for a low carbon future and the part the larger society must play in their practices and attitudes towards efficient use of energy. The increased access to technology can be used as a platform to galvanize broad based support for reducing gas flaring in the oil and gas industry which has been labelled with such practices.

In the light of the above, the institutions of learning and training must strive to build and structure their academic curriculums to reflect the modern challenges of gas flaring in the extractive industry as a matter of priority and necessity. There is need for a breed broad range of specialists to address this recurring issue and due attention must be given to retraining and development respectively. As the oil and gas industry is evolving, there have also been corresponding effects on the processes. It is thus imperative to continuously develop methods of exploration that are sustainable and more environmentally friendly which is in alignment with the sustainable development ideology.

The need to minimize negative aspects of oil and gas operations, notably gas flaring, has been one of the most recurring and notable issues connected with the upstream petroleum sector. It is noteworthy that government and industry are engaging at different levels in this regard. In other words it is imperative for the key stakeholders, in this instance, government and industry to achieve a balance between the prescriptive and performance based approaches to regulate the gas flaring component connected with the oil and gas processes. In the former approach, government has ample latitude to infuse a culture of regulatory compliance, whilst in the latter, emphasis should be placed on setting minimum objective targets or goals applicable to the industry players. 
Hence, there is wide anticipation in the public domain that the outcomes of such engagement, should transcend the traditional adversary models in order to yield more innovative solutions in the long term. The re-emerging concept of sustainable development is also key in this regard, and thus necessitates a broadening of discussions on environmental protection from merely reducing pollution, but also extend to issues of; recycling, renewable energy and conservation. The bottom line being that, the various strategies being adopted must provide sustainable and multiple solutions to solve many of the complexities surrounding resource utilization and conservation practices.

On a final note, gas flaring guidelines geared at fostering industry best practices should be developed through; consistent engagement, information exchange fora and discussions between industry, government community, credible non-governmental organization and other interested stakeholders. The affected companies should conform to a more holistic approach to elevating industry best practices on mitigating the high incidence of gas flaring, coupled with other health and safety practices. This culture should be encouraged regardless of the stage or phase of the oil and gas operations. Thus, it is hoped that all the stakeholders will increasingly appreciate the need to put an end to gas flaring, a common problem which affects all in different ways.

\section{References}

Aluko, B., \& Oyebode, G (2007). A practical insight to cross-border gas regulation work. Global Legal Group.

Associated Gas Re-injection Act 1979 (Cap A26, Laws of the Federation of Nigeria, 2010).

Begg, K. G., van der Woerd, F., \& Levy, D. L. (2005). The business of climate change. Sheffield, UK: Greenleaf.

Bradley, R., \& Baumert, K. A. (Eds.) (2005). Growing in the greenhouse: Protecting the climate by putting development first. Washington, DC: World Resources Institute.

Climate Justice (2006). "Gas flaring in Nigeria: A human rights, environmental and economic monstrosity".http:/www.climatelaw.org/gas.flaring/reportlexec.summary.html.

Gerner, F. (2004). A framework for reducing gas flaring and venting. Presentation at Global Gas Flaring Reduction's Regulatory Capacity Building Workshop in Bandung, Indonesia, March 15 - 16, 2004.

Herzog, T., Baumert, K., \& J. Pershing, J. (2006). Target: Intensity - An analysis of greenhouse gas intensity targets. World Resource Institute (WRI) Report.

Jorgenson, A. K. (2006). Global warming and the neglected greenhouse gas: A cross-national study of the social causes of methane emissions intensity. Social Forces, 84 (3), 1779-1798.

Kafada, A.A. (2012). Environmental impacts of oil exploration and exploitation in the Niger Delta of Nigeria. Global Journal of Science Frontier Research Environment \& Earth Sciences, 12 (3), 2249-4626.

Kaldany, R. (2006). "Global gas flaring reduction: A time for action!" A Keynote Speech Presented at Global Forum on Flaring and Gas Utilization, Held in Paris on December 13, 2006.

Petroleum Act 1969; Petroleum (Drilling and Production) Regulations 1969, Cap P12, Laws of the Federation of Nigeria (2004).

Malumfashi, G. I. (20070. Phase-out of gas flaring in Nigeria by 2008: The prospects of a multi-win Project. The Petroleum Training Journal, 4(2). Available at: http://www.nccrtrade.org/publications/.

Ojide, G.M. (2010). Gas industry in Nigeria: Its impact and sustainability in the economy. Covenant Journal of Business and Social Sciences, 3 (1 \&2), 79-106.

Omorogbe, Y. (2003). Oil and gas law in Nigeria. Malthouse Press.

Oyewunmi, O. A. (2009). Practical strategies for managing the incidence of gas flaring and associated issues in the international oil and gas industry. Centre for Energy, Petroleum and Mineral Law and Policy (CEPMLP), University of Dundee, Scotland, United Kingdom (Unpublished Dissertation).

Shinsato, A. (2005). Increasing the accountability of transnational corporations for environmental harms: The petroleum industry in Nigeria. Northwestern University Journal of International Human Rights, Chicago.

World Bank (2004). Report consultation with stakeholders on global gas flaring reduction. Report No. 1, Washington.

Zyuzev, R. (2008). Gas market liberalization as a key driver of change of European gas market and its influence on the strategies of main players. Centre International De Formation European. 
ISSN 2039-2117 (online)

ISSN 2039-9340 (print)
Mediterranean Journal of Social Sciences MCSER Publishing, Rome-Italy
Vol 7 No 4 July 2016 